\title{
Improved anode two-phase mass transfer management of direct methanol fuel cell by the application of graphene aerogel
}

Weijian Yuan ${ }^{1}$, Xuelin Zhang ${ }^{1,2,3}$ *, Yufeng ${ }^{1}$ Zhang $^{2,3}$, Xiaowei Liu ${ }^{1,2,3}$

${ }^{1}$ MEMS Center, Harbin Institute of Technology, Harbin 150001, China

${ }^{2}$ State Key Laboratory of Urban Water Resource and Environment, Harbin Institute of Technology, Harbin 150001, China

${ }^{3}$ Key Laboratory of Micro-systems and Micro-structures Manufacturing of Ministry of Education, Harbin Institute of Technology, Harbin 150001, China

*Corresponding Author: Email: zhangxuelin@hit.edu.cn; Fax: +86-451-86413441; Mailing Address: Weijian Yuan, Building 2A, Science Park of Harbin Institute of technology, No.2 Yikuang Street, Nangang District, Harbin 150001, China Xuelin Zhang, Yufeng Zhang, Xiaowei Liu, Box 328, Harbin Institute of Technology, No.92 West Dazhi Street, Nangang District, Harbin 150001, China

Number of pages: 5

Number of figures: 2

Number of tables: 1 


\section{Characterization Methods}

\subsection{Electrochemical measurements}

For the methanol crossover test we designed, cyclic voltammetry was applied on an electrochemical workstation (CHI660D, Chenhua Shanghai) using a three-electrode cell. A glassy carbon electrode (GCE) with the diameter of $5 \mathrm{~mm}$ served as the working electrode while a $1 \mathrm{~cm} * 1 \mathrm{~cm}$ Pt foil and $\mathrm{Hg} / \mathrm{Hg}_{2} \mathrm{SO}_{4}$ electrode were chosen for counter electrode and reference electrode respectively. For the preparation of working electrode, GCE was first polished by alumina suspensions. The catalyst ink was obtained by dispersing $4 \mathrm{mg}$ commercial Pt/C catalyst (40\%Pt, Johnson Matthey) into $1 \mathrm{~mL}$ isopropyl alcohol uniformly, together with $20 \mu \mathrm{L}$ Nafion (5 wt. \%, DuPont). Then $5 \mu \mathrm{L}$ catalyst slurry was dropped onto the GCE and dried under room temperature. The potential range was $-0.65 \mathrm{~V}$ to $0.55 \mathrm{~V}$, with the scan rate of $0.05 \mathrm{Vs}^{-1}$. The measurements were conducted at $298 \mathrm{~K}$ and the potentials documented were versus the $\mathrm{Hg} / \mathrm{H}_{2} \mathrm{SO}_{4}$ reference electrode.

\subsection{Methanol crossover test}

Methods for electrochemical measurements are as described above. During the test, the reservoir chamber at the anode was filled with a certain concentration of methanol solution, while the chamber connected to the cathode was filled with a fixed volume of $0.5 \mathrm{M} \mathrm{H}_{2} \mathrm{SO}_{4}$ (saturated with nitrogen). A certain voltage was applied to the anode using amperometric i-t method on the electrochemical workstation to maintain the output at $120 \mathrm{~mA} \mathrm{~cm}{ }^{-2}$. After a certain period, cyclic voltammetry was performed on the threeelectrode cell system. According to the CV curve obtained, the methanol concentration 
in the cathode chamber is calibrated. Combining with the volume of the solution in the chamber, we can calculate the amount of methanol permeating from anode to cathode during the operation of $\mu \mathrm{DMFC}$. The method for the concentration calibration is as follows. First, the working electrode is activated in $0.5 \mathrm{M} \mathrm{H}_{2} \mathrm{SO}_{4}$ to achieve a steady response (as shown in FigureS1a). Second, standard solutions of different concentrations of methanol with $0.5 \mathrm{M} \mathrm{H}_{2} \mathrm{SO}_{4}$ were prepared. Then $\mathrm{CV}$ scans with the working electrode were conducted in the different standard solutions. CV curves obtained in the solution of methanol and $0.5 \mathrm{M} \mathrm{H}_{2} \mathrm{SO}_{4}$ show two oxidation peaks, one in the positive scanning direction, the other in the negative direction. According to the results, the relationship between the positive peak current density $I_{f}$ and the methanol concentration can be obtained, and a fitting curve is made. Next, based on the $I_{f}$ value of the $\mathrm{CV}$ measured in the cathode chamber, the corresponding methanol concentration is determined. It is worth noting that the working electrode corrected in the standard solution and the working electrode used in the cathode chamber must be the same electrode. The peristaltic pump was used to circulate the anode methanol solution during the test to maintain the concentration stable. Figure S1b exhibits the curves of performing linear sweep voltammetry (LSV) on the anodes of the test systems corresponding to MEA-JM and MEA-C30GA70, according to which the voltage applied on the anode can be determined to keep the output at $120 \mathrm{~mA} \mathrm{~cm}^{-2}$.

\subsection{Stability test}

Stability test of the two $\mu$ DMFCs with MEA-JM and MEA-C30GA70 were conducted at $298 \mathrm{~K}$, operating with $3 \mathrm{M}$ and $6 \mathrm{M}$ methanol solution respectively. Both $\mu \mathrm{DMFCs}$ 
maintain an output current density of $120 \mathrm{~mA} \mathrm{~cm}^{-2}$, and the value of the output voltage is recorded every $120 \mathrm{~s}$ to obtain the power density-time curve.

\section{Supplementary table and figures}

Table S1. Statistics of methanol concentration and peak power density of $\mu$ DMFCs in this work

\begin{tabular}{ccccc}
\hline & MEA-C100 & MEA-JM & MEA-C30GA70 & MEA-GA100 \\
\hline $\begin{array}{c}\text { Methanol } \\
\text { concentration at 333 } \\
\text { K/ M } \\
\text { Methanol }\end{array}$ & 3 & 3 & 7 & 7 \\
$\begin{array}{c}\text { concentration at } 298 \\
\text { K/ M }\end{array}$ & 3 & 3 & 6 & 6 \\
$\begin{array}{l}\text { Peak power density } \\
\text { at } 333 \mathrm{~K} / \mathrm{mW} \text { cm }^{-2}\end{array}$ & 34.5 & 34.4 & 43.6 & 33.3 \\
$\begin{array}{c}\text { Peak power density } \\
\text { at } 298 \mathrm{~K} / \mathrm{mW} \text { cm }^{-2}\end{array}$ & 20.7 & 19.4 & & \\
\hline
\end{tabular}
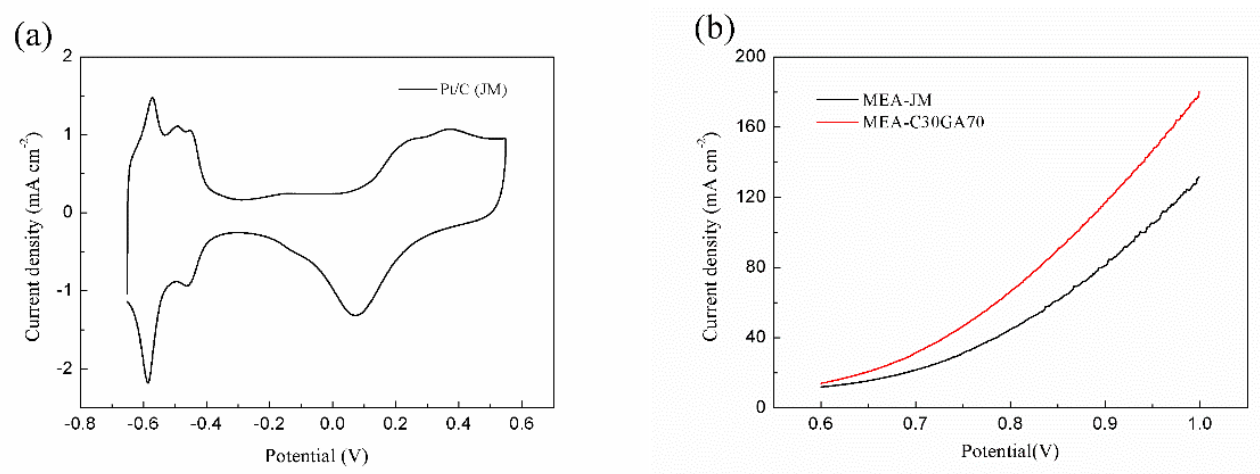

Figure S1. (a) CV curve of the working electrode in $0.5 \mathrm{M} \mathrm{H}_{2} \mathrm{SO}_{4}$; (b) LSVs of the anodes of the test systems corresponding to MEA-JM and MEA-C30GA70 


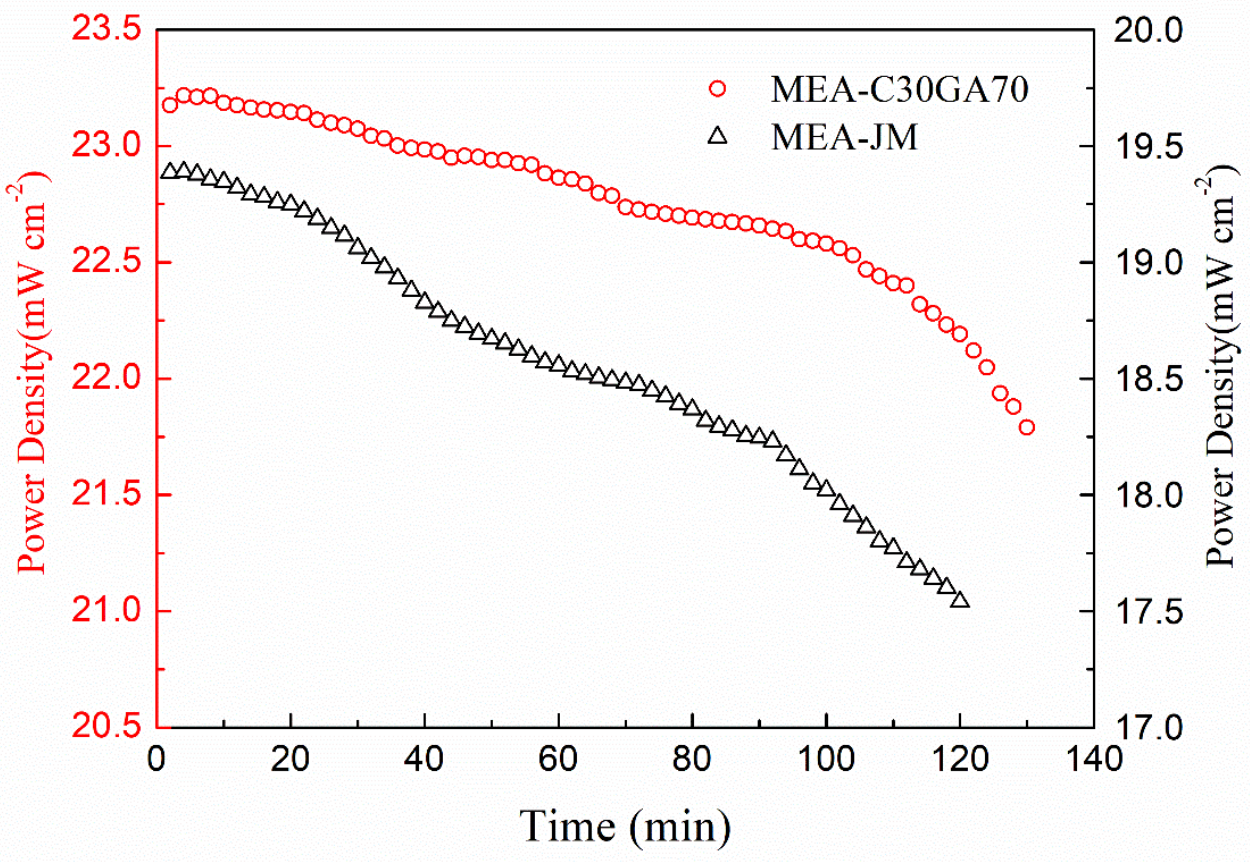

Figure S2. Stability test of the two $\mu \mathrm{DMFCs}$ with an output of $120 \mathrm{~mA} \mathrm{~cm}{ }^{-2}$ 